\title{
Psychiatric morbidity in parents of children with behavioral problems attending child guidance clinic
}

\author{
C Babu T. ${ }^{1}$, Saji K. ${ }^{2}$, Raj Eliza S. ${ }^{*}$ \\ DOI: https://doi.org/10.17511/ijphr.2017.i2.03
}

\author{
1 Tom C Babu, Assistant Surgeon, Department of Psychiatry, Taluk Hospital, Chettikad, Kerala, India. \\ 2 Saji K, Additional Professor, Department of Psychiatry, Government T D Medical College, Alappuzha, Kerala, India. \\ 3* Sharon Raj Eliza, Post Graduate student, Department of Community Medicine, Government TD Medical College, Alappuzha, Kerala, India.
}

Introduction: Psychiatric morbidity in parents can influence behavioral problems in children and behavioral problems in child can cause heightened family distress. Our objectives were to evaluate the frequency and nature of psychiatric morbidities in parents of children with psychiatric illness and to study their association. Methodology: The study sample included parents of children with behavioral problems attending the child guidance clinic, Government Medical College, Kottayam, Kerala. Children were initially screened using Childhood Psychopathology Measurement Schedule and in those screened positive the diagnosis was confirmed using the DCR criteria for ICD -10 . The parents of those children were screened using the General Health Questionnaire-12 and those who scored above cut off were evaluated for psychiatric disorders by taking history doing detailed physical examination and mental status examination. Statistical analysis was done to find the frequency and nature of illnesses and the association between parental and child diagnoses. Results: $61 \%$ of the fathers and $25 \%$ of the mothers had psychiatric morbidity. Significant associations were found between 1) conduct disorders in children with fathers' alcohol dependence and bipolar affective disorder and mothers' depressive disorder 2) ADHD (F90.0) in children with fathers' alcohol harmful use 3) Hyperkinetic conduct disorder(ADHD+CD) in children with fathers' alcohol dependence and bipolar affective disorder and mothers' depression 4) Pervasive developmental disorder in children with fathers' alcohol dependence 5) Mental retardation in children with fathers' alcohol dependence. Conclusion: Parents of children with behavioural problems have higher rate of psychiatric morbidity and there are significant associations between many conditions in parents and their children.

Keywords: Parental psychiatric morbidity, ADHD/hyperkinetic disorders, Conduct disorders

\section{Corresponding Author}

Sharon Raj Eliza, Post Graduate student, Department of Community Medicine, Government TD Medical College, Alappuzha, Kerala, India. Email: sharoneliza123@gmail.com
How to Cite this Article

Babu TC, Saji K, Eliza SR. Psychiatric morbidity in parents of children with behavioral problems attending child guidance clinic. Public Health Rev Int J Public Health Res. 2017;4(2):45-52. Available From

https://publichealth.medresearch.in/index.php/ijphr/ article/view/61

\section{To Browse}

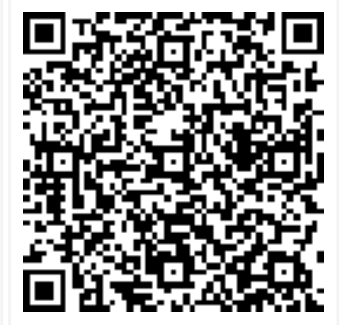

Manuscript Received 2017-04-04

Conflict of Interest No
Review Round 1 2017-04-13

Funding $\mathrm{Nil}$

Review Round 2
2017-04-22
$\begin{gathered}\text { Ethical Approval } \\ \text { Yes }\end{gathered}$

Review Round 3

Plagiarism X-checker $5 \%$
Accepted 2017-04-30

Note

(C) 2017 by Tom C Babu, Saji K, Sharon Raj Eliza and Published by Siddharth Health Research and Social Welfare Society. This is an Open Access article licensed under a Creative Commons Attribution 4.0 International License https://creativecommons.org/licenses/by/4.0/ unported [CC BY 4.0]. 


\section{Introduction}

According to World Health Organisation (WHO) statistics, prevalence of disabling mental illnesses among children and adolescents attending urban health centers ranges between $20-30 \%$ and $13-18 \%$ in rural areas. Out of these $3-4 \%$ are suffering from serious mental illnesses and require treatment [1]. Millions of children and adolescents are exposed to parental mental health problems at any given time [2].

Studies have noted that offspring of mentally ill parents have higher rates of psychiatric diagnoses in childhood and are more likely to show developmental delays, lower academic competence, and difficulty with social relationships [3]. In addition, these offspring are more likely to have mental health problems in adolescence and adulthood [4]. Childhood is the developmental period in which most children are not only living with parents, but are also almost completely dependent on parents for their emotional and physical needs.

\section{Objectives}

01. To evaluate the frequency and nature of psychiatric morbidities in parents of children attending the child guidance clinic.

02. To study the association between the psychiatric morbidity in children with their parental psychiatric morbidity.

\section{Methodology}

Study design: Cross-sectional study.

Study period: $1 / 7 / 2014$ to $30 / 6 / 2015$

Study setting: Child Guidance Clinic (CGC), Department of Psychiatry, Government Medical College, Kottayam, Kerala.

\section{Inclusion criteria for children}

01. Children with a definite diagnosis of psychiatric illness as per the diagnostic criteria for research (DCR-10).

02. Children with age less than 12 years.

03. Children of parents giving consent

\section{Exclusion criteria for children}

01. Adopted children

02. Children who are physically unfit for evaluation.

03. Parents inaccessible.

\section{Inclusion criteria for parents}

01. Biological parents.

02. Parents living with the child.

\section{Exclusion criteria for parents}

01. Parents with severe debilitating physical illnesses.

\section{Study tools}

01. Diagnostic Criteria for research (DCR-10)[5]

02. Childhood Psychopathology Measurement Schedule[6]

03. The General Health Questionnaire - 12 Version (David Goldberg,[7]

04. Kuppuswamy's Socioeconomic Status Scale

A specially designed pro-forma is used for collecting relevant socio demographic and psychiatric details.

The study sample includes parents of children with behavioral problems attending the child guidance clinic (CGC), Government Medical College, Kottayam for the first time, who has satisfied the inclusion and exclusion criteria.

The subjects were explained about the purpose of the study and were included in the study after getting an informed consent. Each child was initially screened using Childhood Psychopathology Measurement Schedule and in those screened positive the diagnosis was confirmed using the DCR criteria for ICD -10 .

The parents of those children with a definite psychiatric illness was initially screened using the General Health Questionnaire-12 and those who are getting a score of 3 and above was further evaluated for psychiatric disorders by taking history, doing detailed physical examination and mental status examination and the diagnosis was confirmed using DCR criteria for ICD-10.

The data was collected and tabulated. Statistical analysis was done using the computer software, Statistical Package for Social Sciences (SPSS) 16.0.

\section{Results}

The study included parents of 200 children from child guidance clinic. The mean age of the children was 8.32 with standard deviation (SD) 1.997. Mean age of father was 37.37 and mean age of mother was 33.09. Out of the total children included in the study $75.5 \%$ of them were males $24.5 \%$ were females. 
Among the 200 fathers 122 had psychiatric morbidity of which most common was harmful use of alcohol in 60 fathers (30\%) followed by alcohol dependence syndrome in 38 fathers (19\%). 8 fathers had co morbid psychiatric disorder along with alcohol use disorder of which mood disorder was commonest. Out of the 200 mothers 50 (25\%) had psychiatric morbidity of which depressive disorders $n=22(11 \%)$ was the most common followed by anxiety disorder $n=18(9 \%)$.

Significant associations were found between 1) conduct disorders in children with fathers' alcohol dependence and bipolar affective disorder and mothers' depressive disorder 2) ADHD (F90.0) in children with fathers' alcohol harmful use 3)Hyperkinetic conduct disorder(ADHD+CD) in children with fathers' alcohol dependence and bipolar affective disorder and mothers' depression 4) Pervasive developmental disorder in children with fathers' alcohol dependence 5) Mental retardation in children with fathers' alcohol dependence and psychosis .

Table-1: showing various psychiatric diagnosis of children attending child guidance clinic

\begin{tabular}{|l|l|l|}
\hline \multicolumn{1}{|c|}{ Diagnosis } & \multicolumn{1}{|c|}{$\begin{array}{c}\text { Number of } \\
\text { children }\end{array}$} & \multicolumn{1}{|c|}{ Percentag } \\
\hline Hyperkinetic disorder(F90.0/ADHD) & 22 & $11 \%$ \\
\hline Specific learning disorder(F81/SLD) & 16 & $8 \%$ \\
\hline Conduct disorders(F91/CDs) & 11 & $5.5 \%$ \\
\hline Mental retardation(MR) & 24 & $12 \%$ \\
\hline Pervasive developmental & 14 & $7 \%$ \\
\hline Disorders(F84/PDDs) & & \\
\hline Bipolar affective disorder(F31/BPAD) & 5 & $2.5 \%$ \\
\hline Depressive disorders(F32/f33) & 3 & $1.5 \%$ \\
\hline Anxiety disorders & 15 & $7.5 \%$ \\
\hline ADHD+SLD(F90.0+F81) & 47 & $23.5 \%$ \\
\hline Hyperkinetic conduct & 27 & $13.5 \%$ \\
\hline disorder(F90.1/ADHD+CD) & & $3 \%$ \\
\hline SLD+CD & 6 & $1 \%$ \\
\hline SLD+ anxiety disorder & 2 & $0.5 \%$ \\
\hline SLD+ others* & 1 & $0.5 \%$ \\
\hline CD+ others* & 1 & $0.5 \%$ \\
\hline MR+ anxiety & 1 & $2.5 \%$ \\
\hline Others* & 5 & $100 \%$ \\
\hline Total & 200 & \\
\hline
\end{tabular}

*Others included 2 children with non-organic sleep disorders, 3 children with post encephalitic sequelae and 2 children with non-organic enuresis

Table-2: Psychiatric morbidity among fathers of children attending child guidance clinic

\begin{tabular}{|l|l|l|}
\hline \multicolumn{1}{|c|}{ Psychiatric morbidity } & Number & Percentage \\
\hline Alcohol dependence syndrome(ADS) & 38 & $19 \%$ \\
\hline Alcohol harmful use & 60 & $30 \%$ \\
\hline Psychotic disorders(F20-F29) & 2 & $1 \%$ \\
\hline Bipolar affective disorders(F31/BPAD) & 7 & $3.5 \%$ \\
\hline Depressive disorders(F32/F33) & 1 & $0.5 \%$ \\
\hline Anxiety disorders(F40-F48) & 6 & $3 \%$ \\
\hline Ads +anxiety disorder & 3 & $1.5 \%$ \\
\hline Alcohol harmful use + anxiety disorder & 2 & $1 \%$ \\
\hline BPAD +ADS & 3 & $1.5 \%$ \\
\hline No disorder & 78 & $39 \%$ \\
\hline Total & 200 & $100 \%$ \\
\hline
\end{tabular}

Table-3: Psychiatric morbidity in mothers attending child guidance clinic

\begin{tabular}{|l|l|l|}
\hline \multicolumn{1}{|c|}{ Psychiatric morbidity } & Number & Percentage \\
\hline Bipolar affective disorder(F31/BPAD) & 4 & $2 \%$ \\
\hline Depressive disorders(F32/F33) & 22 & $11 \%$ \\
\hline Anxiety disorders(F40-F48) & 18 & $9 \%$ \\
\hline Depression +anxiety disorders & 5 & $2.5 \%$ \\
\hline Mental retardation & 1 & $0.5 \%$ \\
\hline No disorders & 150 & $75 \%$ \\
\hline Total & 200 & $100 \%$ \\
\hline
\end{tabular}

Table-4: Association between paternal psychiatric illness and child ADHD

\begin{tabular}{|c|c|c|c|}
\hline Child diagnosis & $\begin{array}{l}\text { Paternal } \\
\text { diagnosis }\end{array}$ & $\begin{array}{c}P \\
\text { value }\end{array}$ & $\begin{array}{c}\text { Chi square } \\
\text { value }\end{array}$ \\
\hline \multirow[t]{6}{*}{ ADHD } & $\mid \begin{array}{l}\text { Alcohol } \\
\text { dependence }\end{array}$ & 0.085 & 2.972 \\
\hline & Depression* & 1.000 & 0.124 \\
\hline & Anxiety* & 1.000 & 0.043 \\
\hline & Psychosis* & 1.000 & 0.250 \\
\hline & BPAD* & 0.606 & 1.301 \\
\hline & $\begin{array}{l}\text { Alcohol harmful } \\
\text { use }\end{array}$ & 0.041 & 4.172 \\
\hline \multirow[t]{6}{*}{ ADHD with conduct disorder } & $\begin{array}{l}\text { Alcohol } \\
\text { dependence }\end{array}$ & 0.011 & 6.389 \\
\hline & Depression* & 1.000 & 0.157 \\
\hline & Anxiety* & 0.366 & 1.817 \\
\hline & Psychosis* & 1.000 & 0.315 \\
\hline & BPAD* & 0.005 & 12.009 \\
\hline & $\begin{array}{l}\text { Alcohol harmful } \\
\text { use }\end{array}$ & 0.104 & 2.630 \\
\hline \multirow[t]{6}{*}{$\begin{array}{l}\text { ADHD with specific learning } \\
\text { disorder }\end{array}$} & $\begin{array}{l}\text { Alcohol } \\
\text { dependence }\end{array}$ & 0.790 & 0.071 \\
\hline & Depression* & 1.000 & 0.309 \\
\hline & Anxiety* & 0.464 & 1.344 \\
\hline & Psychosis* & 0.416 & 0.789 \\
\hline & BPAD* & 1.000 & 0.072 \\
\hline & $\begin{array}{l}\text { Alcohol harmful } \\
\text { use }\end{array}$ & 0.606 & 0.266 \\
\hline
\end{tabular}


The criteria for diagnosing disorders were according to the Diagnostic Criteria for Research (DCR 10) accompanying the ICD 10 . But some of the names of the diagnoses have been used interchangeably with DSM-5 since most of the studies on childhood disorders were based on DSM.

Table-5: Association between paternal and child psychiatric illness (except ADHD)

\begin{tabular}{|c|c|c|c|}
\hline Child diagnosis & Paternal diagnosis & P value & Chi square value \\
\hline \multirow[t]{6}{*}{ Conduct disorders } & Alcohol dependence* & 0.000 & 20.334 \\
\hline & Depression* & 1.000 & 0.267 \\
\hline & Anxiety* & 0.125 & 3.094 \\
\hline & Psychosis* & 1.000 & 0.537 \\
\hline & BPAD* & 0.007 & 9.651 \\
\hline & Alcohol harmful use & 0.713 & 0.135 \\
\hline \multirow[t]{6}{*}{ PDD } & Alcohol dependence* & 0.025 & 4.0903 \\
\hline & Depression* & 1.000 & 0.087 \\
\hline & Anxiety* & 1.000 & 0.019 \\
\hline & Psychosis* & 1.000 & 0.176 \\
\hline & BPAD* & 1.000 & 0.915 \\
\hline & Alcohol harmful use & 0.982 & 0.001 \\
\hline \multirow[t]{6}{*}{ MR } & Alcohol dependence* & 0.007 & 6.803 \\
\hline & Depression* & 1.000 & 0.170 \\
\hline & Anxiety* & 0.372 & 1.974 \\
\hline & Psychosis* & 0.020 & 11.912 \\
\hline & BPAD* & 1.000 & 0.172 \\
\hline & Alcohol harmful use & 0.083 & 3.002 \\
\hline \multirow[t]{6}{*}{ SLD } & Alcohol dependence & 0.850 & 0.036 \\
\hline & Depression* & 0.330 & 2.041 \\
\hline & Anxiety* & 0.345 & 1.156 \\
\hline & Psychosis* & 1.000 & 0.995 \\
\hline & BPAD* & 0.170 & 2.519 \\
\hline & Alcohol harmful use & 0.424 & 0.640 \\
\hline \multirow[t]{6}{*}{ BPAD } & Alcohol dependence* & 1.000 & 0.012 \\
\hline & Depression* & 1.000 & 0.026 \\
\hline & Anxiety* & 0.246 & 2.074 \\
\hline & Psychosis* & 1.000 & 0.052 \\
\hline & BPAD* & 0.228 & 2.420 \\
\hline & Alcohol harmful use & 1.000 & 0.290 \\
\hline \multirow[t]{6}{*}{ Depression } & Alcohol dependence* & 1.000 & 0.859 \\
\hline & Depression* & 1.000 & 0.015 \\
\hline & Anxiety* & 0.157 & 2.540 \\
\hline & Psychosis* & 1.000 & 0.031 \\
\hline & BPAD* & 1.000 & 0.160 \\
\hline & Alcohol harmful use* & 1.000 & 0.008 \\
\hline
\end{tabular}

Table-6: Association between maternal and child psychiatric illness (except ADHD)

\begin{tabular}{|l|l|l|l|}
\hline Child diagnosis & Maternal diagnosis & P value & Chi square value \\
\hline
\end{tabular} \begin{tabular}{|l|l|l|l|}
\hline Conduct disorder & Psychosis* & 1.000 & 0.537 \\
\cline { 2 - 4 }
\end{tabular}

\begin{tabular}{|l|l|l|}
\hline Bipolar* & 0.062 & 2.224 \\
\hline
\end{tabular}

\begin{tabular}{|c|c|c|c|}
\hline & Depression & 0.028 & 4.837 \\
\hline & Anxiety & 0.524 & 0.405 \\
\hline & Intellectual disability* & 0.210 & 3.781 \\
\hline Id & Psychosis* & 0.270 & 2.054 \\
\hline & Bipolar* & 1.000 & 0.027 \\
\hline & Depression* & 1.000 & 0.002 \\
\hline & Anxiety & 0.093 & 2.814 \\
\hline & Intellectual disability* & 1.000 & 0.170 \\
\hline Pdd & Psychosis* & 1.000 & 0.176 \\
\hline & Bipolar* & 1.000 & 0.725 \\
\hline & Depression* & 1.000 & 0.015 \\
\hline & Anxiety* & 0.700 & 0.471 \\
\hline & Intellectual disability* & 1.000 & 0.087 \\
\hline Specific learning disorder & Psychosis* & 0.552 & 0.264 \\
\hline & BPAD* & 1.000 & 0.241 \\
\hline & Depression* & 0.511 & 0.706 \\
\hline & Anxiety & 0.222 & 1.491 \\
\hline & Intellectual disability* & 1.000 & 0.495 \\
\hline Bipolar affective disorder(BPAD) & Psychosis* & 1.000 & 0.052 \\
\hline & BPAD* & 1.000 & 0.214 \\
\hline & Depression* & 0.520 & 0.186 \\
\hline & Anxiety* & 0.461 & 0.364 \\
\hline & Intellectual disability* & 1.000 & 0.026 \\
\hline Depression & Psychosis* & 1.000 & 0.031 \\
\hline & BPAD* & 0.116 & 2.825 \\
\hline & Depression* & 0.354 & 1.026 \\
\hline & Anxiety* & 1.000 & 0.396 \\
\hline & Intellectual disability* & 1.000 & 0.015 \\
\hline Anxiety & Psychosis* & 1.000 & 0.176 \\
\hline & BPAD* & 0.493 & 0.229 \\
\hline & Depression* & 1.000 & 0.015 \\
\hline & Anxiety* & 0.404 & 0.898 \\
\hline & Intellectual disability* & 1.000 & 0.087 \\
\hline
\end{tabular}

Table-7: Association between maternal psychiatric illness and child ADHD

\begin{tabular}{|l|l|l|l|}
\hline \multirow{5}{*}{ ADHD } & Psychosis* & 1.000 & 0.250 \\
\cline { 2 - 4 } & BPAD* & 0.602 & 1.030 \\
\cline { 2 - 4 } & Depression* & 0.745 & 0.412 \\
\cline { 2 - 4 } & Anxiety* & 0.479 & 1.175 \\
\cline { 2 - 4 } & Intellectual disability* & 1.000 & 1.24 \\
\hline ADHD with conduct disorder & Psychosis* & 1.000 & 0.315 \\
\cline { 2 - 4 } & BPAD* & 0.077 & 4.110 \\
\cline { 2 - 4 } & Depression* & 0.008 & 6.954 \\
\cline { 2 - 4 } & Anxiety* & 0.524 & 0.337 \\
\cline { 2 - 4 } & Intellectual disability* & 1.000 & 0.156 \\
\hline \multirow{5}{*}{ ADHD with SLD } & 0.416 & 0.789 \\
\hline & Psychosis* & 1.000 & 0.010 \\
\cline { 2 - 4 } & BPAD* & 0.630 & 0.431 \\
\cline { 2 - 4 } & Depression* & 0.756 & 0.097 \\
\cline { 2 - 4 } & Anxiety & 0.309 \\
\cline { 2 - 4 } & Intellectual disability* & 1.000 & 0.30 \\
\hline
\end{tabular}


Test used was Pearson chi square test, $\mathrm{df}=1, \mathrm{p}$ value significant level $<0.05$ (*fischer's exact test value).

\section{Discussion}

In our study total of 122 fathers and 50 mothers had psychiatric morbidity which constitute $43 \%$ of parents of either sex. This is in correspondence with the study done in Philipps University Marburg Germany which showed $48.3 \%$ of parents of either sex had psychiatric morbidity [8]. Most common psychiatric morbidity among fathers was harmful use of alcohol(30\%) followed by alcohol dependence syndrome in 38 fathers (19\%). This is in accordance with the study by Philipps University Marburg Germany which showed $20.7 \%$ of substance dependence among parents of children with psychiatric disorders.Among the mothers depressive disorder $n=22(11 \%)$ was the most common psychiatric morbidity followed by anxiety disorder $\mathrm{n}=18(9 \%)$ [8]. As per a study from a south Indian rural population prevalence of depressive disorder was $14.82 \%$ and anxiety was $4 \%$ [9]. Significant association was found between, ADHD in children with fathers' alcohol harmful use $(p=0.041)$. A study done in US found that there is significant association between ADHD in children and fathers' substance use disorder. In this study $29 \%$ of children with ADHD had their fathers having substance use disorder [10]. In this study there was significant association between ADHD with conduct disorder (CD) in children and fathers' alcohol dependence $(p=0.011)$ and bipolar affective disorder $(p=0.005)$ and mothers' depression $(p=0.008)$. The US study also found similar association with $31.5 \%$ of children with ADHD and conduct disorder had their fathers having substance use disorder and $43.3 \%$ of mothers having mood disorder [10]. Mental retardation in children was significantly associated with fathers' alcohol dependence $(p=0.007)$ and psychosis $(p=0.020)$. An Indian study on parents of children with mental retardation found significant association between mental retardation in children and dysthymia , anxiety disorder and depression in parents.Substance use disorder is highly co-morbid with all these conditions [11].

\section{Conclusion}

Psychiatric illnesses in parents represent a risk for children in the family. These children have a higher risk for developing behavioral problems than other children.
Medical, mental health or social service professionals working with mentally ill adults need to inquire about the children and adolescents, especially about their mental health and emotional development.

\section{Reference}

01. WHO. The World Health Report 2000- Health Systems- Improving performance. GenevaWorld Health Organization. 2000.

[Crossref]

02. Creswell C, Brereton J. Community mental health services and the children of service users. Clinical Psychology Forum. 2000;144;4-6. [Crossref]

03. Oyserman D, Mowbray CT, Meares PA, Firminger KB. Parenting among mothers with a serious mental illness. American Journal of Orthopsychiatry. 2000;70(3)296-315.

[Crossref]

04. Weissman, Myrna M. Offspring of depressed parents- 10 years later. Archives of General Psychiatry. 1997;54(10)932.

[Crossref]

05. WHO. ICD 10- International Classification of Diseases, Diagnostic Criteria for Research. Geneva- World health Organisation. 2003. [Crossref]

06. Savita Malhotra, V K Varma et al. Childhood psychopathology measurement schedule development and standardization. Indian J Psychiatry. 1988;30(4)325-31.

[Crossref]

07. Goldberg DP, Gater R, et al. The Validity Of Two Versions of The GHQ In The Who Study of Mental Illness In General Health Care. Psychological Medicine. 1997;27(1)191-7. doi: $10.1017 /$ S0033291796004242 [Crossref]

08. Jacob CP, Romanos J. Co-morbidity of adult attention-deficit/hyperactivity disorder with focus on personality traits and related disorders in a tertiary referral center. European Archives of Psychiatry and Clinical Neurosciences. 2007;257(6)309-317.

DOI: $\quad 10.1007 / \mathrm{s} 00406-007-0722-6 \quad$ [Crossref] 
09. Rao TSS, Darsan MS, et al. Suttur study- An epidemiological study of psychiatric disorders in south Indian rural population. Indian Journal of Psychiatry. 2014;56(3)238-245.

doi: 10.4103/0019-5545.140618 [Crossref]

10. Chronis AM, Lahey BB, Pelham WE, Kipp $H L$, Baumann BL, Lee SS. Psychopathology \& substance abuse in parents of young children with attention deficit/hyperactivity disorder. J Am Acad Child Adolesc Pychiatry. 2003;42(12)1424-32.

DOI: $\quad 10.1097 / 00004583-200312000-00009$ [Crossref]

11. Chandorkar H, Chakraborty PK. Psychological Morbidity of Parents of Mentally Retarded Children. Indian Journal of Psychiatry. 2000;42(3)271-274, PMCID: PMC2958351.

[Crossref] 